\title{
Manipulation of familiarity reveals a necessary lexical component of the word-stem completion priming effect
}

\author{
BRADLEY R. POSTLE and SUZANNE CORKIN \\ Massachusetts Institute of Technology, Cambridge, Massachusetts
}

\begin{abstract}
These experiments were motivated by the idea that many types of nondeclarative memory are byproducts arising from the plasticity that is inherent in much of the nervous system. We hypothesized that two types of repetition priming, word-stem completion (WSC) priming and perceptual identification (PI) priming, rely on different mechanisms because the WSC task and the PI task engage different cognitive and brain processes. We tested this hypothesis by manipulating word familiarity. The results, impaired WSC priming but intact PI priming with unfamiliar words, indicate that WSC priming relies primarily on a modification mechanism, whereas PI priming relies primarily on an acquisition mechanism. Our conclusions are consistent with component processes theories of nondeclarative memory.
\end{abstract}

Repetition priming occurs when prior exposure to a stimulus biases or facilitates the processing of that stimulus on subsequent exposures. Experimental paradigms that reveal repetition priming include word-stem completion (WSC; Warrington \& Weiskrantz, 1970), wordfragment completion (Tulving, Schacter, \& Stark, 1982), perceptual identification (PI; Jacoby \& Dallas, 1981; Soloman \& Postman, 1952), word judgment (Dorfman, 1994), and pattern priming (Gabrieli, Milberg, Keane, \& Corkin, 1990; Musen \& Treisman, 1990). This report will focus on WSC and PI. WSC priming is demonstrated when exposure to a word in a study list increases the likelihood that the subjects will complete a three-letter stem to that word. PI priming is demonstrated when subjects can identify previously studied words or pictures at shorter exposure durations than unstudied words or pictures. Theories that seek to explain these examples of nondeclarative (Squire, Knowlton, \& Musen, 1993) or implicit (Graf \& Schacter, 1985) memory fall into four general categories: transfer-appropriate processing, memory systems, component processes, and postperceptual selection. Transfer-

This work was supported by NIH Grant AG06605. B.R.P. received support from a National Science Foundation graduate fellowship. The MIT Clinical Research Center is supported by NIH Grant RR00088. We acknowledge gratefully the assistance of Berenice Belizaire, Jennifer Glos, Youjeong Kim, Eunsil Paik, Saladin Patterson, and Cicely Pickett with stimulus development and data collection, of Mark Snow with computer programming, of Joseph J. Locascio with statistical consulting, of Michael Ullman with developing word frequency counts, and of John Gabrieli, Maggie Keane, Geoff Loftus, Molly Potter, Dan Schacter, Mieke Verfaille, and three anonymous reviewers for helpful discussions about this research and/or for commenting on an earlier draft of this manuscript. Correspondence concerning this article should be addressed to B. R. Postle, Department of Neurology, University of Pennsylvania Medical Center, 3 West Gates, Area 9, 3400 Spruce Street, Philadelphia, PA 19104-4283 (e-mail: postle@mail.med. upenn.edu). appropriate processing theories are typically associated with cognitive science principles derived from hypothesized mental procedures, such as the principle of levels of processing (e.g., Blaxton, 1989; Roediger, 1990). Memory systems theories arise from the neuropsychological approach of interpreting dissociations between tasks as evidence that discrete systems underlie performance on these tasks (e.g., Keane, Gabrieli, Fennema, Growdon, \& Corkin, 1991; Schacter, 1994). Component processes theories emphasize the importance of understanding the processes that underlie performance of the tasks in which nondeclarative memory is displayed (e.g., Tenpenny \& Shoben, 1992; Weldon, 1991; Witherspoon \& Moscovitch, 1989). Postperceptual selection theories posit that repetition priming effects arise from bias effects that occur at the level of response selection (Masson \& MacLeod, 1996; Ratcliff \& McKoon, 1997; Ratcliff, McKoon, \&Verwoerd, 1989).

The differences between the first three groups of theories that are germane to this report lie in the mechanisms that each proposes as being principally responsible for WSC priming and PI priming. (The fourth category, postperceptual selection theories, are considered in the subsequent paragraph.) These mechanisms are acquisition mechanisms and modification mechanisms ${ }^{1}$ (as characterized by Bowers, 1996). Acquisition models posit that repetition priming results from the construction of new memory representations from study episodes. Illustrative of these models are the hypotheses of Roediger and colleagues (Rajaram \& Roediger, 1993; Roediger, 1990), who have asserted that many types of repetition priming are data-driven effects whose magnitude is positively related to the degree of perceptual continuity of stimuli between study and test; of Squire and colleagues (Haist, Musen, \& Squire, 1991; Hamann \& Squire, 1996; Squire et al., 1992), who suggest that visual repetition priming relies on transient change in perceptual circuits in posterior visual cortex; and of Schacter (e.g., Schacter, 1994), 
Table 1

Mechanisms Hypothesized by Three Classes of Theories to be Principally Responsible for Word-Stem Completion and Perceptual Identification Priming

\begin{tabular}{lccc}
\hline & & \multicolumn{3}{c}{ Theory } & \\
\cline { 2 - 4 } \multicolumn{1}{c}{ Task } & $\begin{array}{c}\text { Transfer-Appropriate } \\
\text { Processing }\end{array}$ & $\begin{array}{c}\text { Memory } \\
\text { Systems }\end{array}$ & $\begin{array}{c}\text { Component } \\
\text { Processes }\end{array}$ \\
\hline $\begin{array}{l}\text { Word-stem completion } \\
\text { Perceptual identification }\end{array}$ & $\begin{array}{c}\text { acquisition } \\
\text { acquisition }\end{array}$ & $\begin{array}{c}\text { acquisition } \\
\text { acquisition }\end{array}$ & $\begin{array}{c}\text { modification } \\
\text { acquisition }\end{array}$ \\
\hline
\end{tabular}

who proposes that a system of perceptual representation mechanisms supports learning in repetition priming tasks. Modification models, in contrast, assert that priming effects arise from study-induced activation or modification of mnemonic representations (Diamond \& Rozin, 1984; Graf, Squire, \& Mandler, 1984; Shimamura \& Squire, 1984). These models derive from the activation (or "hot tubes") models of the 1970s (Atkinson \& Juola, 1974; Forbach, Stanners, \& Hochhaus, 1974; Meyer \& Schvanaveldt, 1971; Morton, 1970; Rozin, 1976). The way that these two models map onto transfer-appropriate processing, memory systems, and component processes theories is illustrated in Table 1. The important distinction that arises from this comparison is that transfer-appropriate processing and memory systems theories (although they differ in other respects) each posit that acquisition mechanisms are principally responsible for WSC priming and PI priming. ${ }^{2}$ Component processes theories, on the other hand, view WSC priming and PI priming as reflecting plastic change that occurs in largely distinct processes. The experiments presented in this report were performed to test the predictions of these different classes of theories, as they relate to WSC priming and PI priming.

Postperceptual selection theories are embodied by the writings of Ratcliff and McKoon (Ratcliff \& McKoon, 1997; Ratcliff et al., 1989) and of Masson and MacLeod (1996). A detailed assessment of postperceptual selection theories is beyond the scope of this report. These theories, in our view, have yet to account for the considerable body of research that is consistent with a perceptual explanation of PI priming (as reviewed, for example, in Reinitz \& Alexander, 1996). In addition, the bias effects reported by proponents of this theory may arise as a direct result of the forced-choice testing methods that they employ (e.g., Masson \& MacLeod, 1996; Ratcliff \& McKoon, 1997). Their tasks feature an explicit choice component that does not exist in conventional repetition priming designs, and therefore, their results may be vulnerable to declarative memory contamination (Light \& Kennison, 1996a, 1996b; McKoon \& Ratcliff, 1996). Because of this, we believe that postperceptual selection theories are not germane to the issues considered in the present report.

The research presented in this paper was motivated by the hypothesis that nondeclarative memory is a by-product of the plasticity intrinsic to the central nervous system and, thus, that it can be observed in virtually any process that the central nervous system carries out (e.g., motor control, lexical search, and visual perception). We believe, in a view akin to component process theories, that careful analysis of the demands of the tasks in which nondeclarative memory is displayed represents the best way to elucidate the cognitive and neural systems that support different examples of this mnemonic phenomenon. The task analysis approach affords greater analytic precision and greater predictive power than do alternative theoretical approaches, whose models are limited to a very general level of description (e.g., data-driven vs. conceptually driven priming in transfer-appropriate processing models and perceptual vs. conceptual memory systems in memory systems taxonomies; see Tenpenny \& Shoben, 1992).

Our task analysis led to the observation that WSC priming requires subjects to engage in a lexical search to find a word that completes a three-letter stem. We hypothesized, therefore, that the learning observed in WSC priming may arise from modification mechanisms operating at the level of the mental lexicon. PI priming, on the other hand, places a premium on the identification of stimuli that are presented near the limits of temporal resolution of the visual system. The mechanisms that support learning on this task, therefore, may be acquisition mechanisms that operate at relatively low levels of the visual system (Keane et al., 1991; Reinitz \& Alexander, 1996). These observations led us to hypothesize that the mechanisms that support learning with repetition of stimuli are different for the two tasks, just as the mechanisms that are recruited by a lexical search task are largely different from the mechanisms recruited by a visual discrimination task. This hypothesis is inconsistent with the assumption, made explicit in the writings of many transfer-appropriate processing (e.g., Rajaram \& Roediger, 1993; Richardson-Klavehn, Gardiner, \& Java, 1994; Roediger, Weldon, Stadler, \& Rigler, 1992) and memory systems (e.g., Hamann \& Squire, 1996; Keane et al., 1997; Schacter, 1994) theorists, that WSC priming is a perceptual phenomenon supported by the same mechanisms as those that support PI priming. We tested this hypothesis by manipulating the familiarity of the verbal stimuli in these two repetition priming tasks. Transfer-appropriate-processing and memory systems theories predicted that the two repetition priming tasks would be affected in the same way by this manipulation, because unfamiliar words do not differ perceptually from familiar words and early (prelexical) stations of the visual system would be expected to process meaningful and nonmeaningful letter strings in the same way. Our component processes theory, in contrast, hypothesized that the two tasks arise primarily from distinct mechanisms (PI 
priming from acquisition, WSC priming from modification), and therefore predicted that the two would be affected differently by the manipulation of familiarity.

Familiarity manipulations permit a direct test of modification models because these models assume that priming requires the existence of mental representations corresponding to the stimuli with which priming can be expressed. Strong interpretation of a modification model of a priming phenomenon would yield a prediction of absent priming with unfamiliar stimuli, because these stimuli lack corresponding mental representations. Many memory researchers have employed this logic to elucidate the mechanisms of memory. The perceptual nature of PI priming has been demonstrated by robust priming effects with pseudowords or unfamiliar words in healthy subjects (Bowers, 1994, 1996; Kirsner \& Smith, 1974; Rueckl, 1990; Soloman \& Postman, 1952; Whitlow \& Cebollero, 1989; Whittlesea \& Cantwell, 1987) and in amnesic subjects (Cermak, Verfaellie, Milberg, Letourneau, \& Blackford, 1991; Haist et al., 1991; Keane, Gabrieli, Growdon, \& Corkin, 1994; Postle \& Corkin, 1998). An absence of nonword lexical decision priming was interpreted by Forbach and colleagues (Forbach et al., 1974) to be consistent with a modification model of lexical decision priming. Repetition priming with novel dot pattern completion (Gabrieli, Milberg, et al., 1990) and identification (Musen \& Treisman, 1990) tasks has demonstrated robust perceptual priming with unfamiliar nonlinguistic stimuli. Demonstrations of intact novel-stimulus priming in Alzheimer's disease (AD) with PI (Keane et al., 1994) and with patterns (Postle, Corkin, \& Growdon, 1996 ) indicate that these manifestations of acquisition mechanisms are supported by the striate and peristriate visual cortical regions that are relatively spared at early stages of the disease.

Direct comparisons of WSC and PI have shown that they dissociate by manipulation of disease state $(\mathrm{AD}$; Keane et al., 1991) and age (LaVoie \& Light, 1994). These between-group dissociations do not, however, provide any insight as to the mechanistic differences that may underlie these dissociations. A demonstration of a withingroup dissociation resulting from the manipulation of a stimulus-related independent variable could, therefore, make an important contribution to our understanding of the precise nature of the differences between PI and WSC priming. Although earlier writings have proposed that a modification mechanism is responsible for WSC priming (Graf et al., 1984; Shimamura \& Squire, 1984), none of these reports provided a test of this hypothesis. To our knowledge, the only previous report of impaired WSC priming with unfamiliar stimuli is one from our laboratory that was not conducted in the context of a test of models of repetition priming mechanisms (Gabrieli, Keane, $\&$ Corkin, 1990). This report, therefore, together with a similar study in amnesic patients (Postle \& Corkin, 1998) represents the first test of the modification model of WSC priming.
In this report we present four experiments. Experiment 1 tested the hypothesis that WSC priming relies on a modification mechanism by manipulating stimulus familiarity. Experiment 2 tested alternative explanations of the result of Experiment 1, by testing the effects of the familiarity manipulation on two methodological variants of the WSC test. Experiment 3 tested the effects of the familiarity manipulation on PI priming and illustrated a dissociation between PI and WSC priming. Experiment 4 tested the reliability of the result from Experiment 3 by testing the effects of the familiarity manipulation on PI priming when the PI test is modified so that its baseline levels are comparable with those in the WSC test.

\section{GENERAL METHOD}

\section{Subjects}

The subjects participating in each experiment were members of the MIT community who were college graduates or actively working toward a college degree, had learned English as their first language, and had normal or corrected-to-normal vision (Snellen visual acuity range, $20 / 20-20 / 25$ ).

\section{Design}

The principal independent variable in each experiment was the familiarity of the word stimuli (familiar or unfamiliar), and the principal dependent variable was priming, calculated as performance on studied minus that on unstudied items. Each experiment employed a between-subjects design to avoid declarative memory contamination of the data, because previous experience indicated that young subjects quickly realize that their memory is being tested when they are given multiple priming tests. In Experiment 1, two groups of subjects were tested on a WSC cued-recall test (a test of declarative memory).

\section{Materials}

To assemble an unfamiliar-word stimulus set, we selected 104 English language words from Bowler (1992), Evans and Berent (1993), and The American Heritage Dictionary (1991; Appendix A) that were judged to be unfamiliar to a typical college undergraduate. The mean frequency of the unfamiliar words was 0 per 44 million, ${ }^{3}$ the mean length was 8.2 letters. Before the experiment began, we confirmed that these words were low-usage words by distributing a list of 104 three-letter stems, corresponding to our 104 words, to 102 subjects (different from those whose data are presented in this report), 18-35 years of age, and instructing them to complete each stem to the first word that came to mind. None of the words from the unfamiliar list was used to complete a stem. To assemble the familiar-word stimulus set, we selected 104 English language words that were judged to be familiar to a typical college undergraduate (Appendix B). The mean frequency of the familiar words was 16.9 per 44 million; the mean length was 7.9 letters. Of the 104 words in each stimulus set, 80 were divided into four lists of 20 words each. Each list contained roughly the same number of short words ( 8 letters or less) and long words (more than 8 letters). The remaining 24 words were used as buffer words, with 3 placed at the beginning and 3 at the end of each 20 -word list to dampen primacy and recency effects.

\section{Apparatus}

WSC testing (Experiments 1 and 2) was performed with a Macintosh IIcx. PI testing (Experiments 3 and 4) was performed with high-speed random access projectors (Kodak EktaPro 7000) fitted with high-speed shutters (Gerbrands G1166) that were computer 
controlled (Macintosh IIcx), projecting onto a rear projection screen. Word stimuli in all the experiments were presented in all capital letters in 48-point Helvetica font. Each subject sat approximately 24 in. from the screen.

\section{Procedure}

The subjects participated in a WSC priming test, a WSC recall test, or a PI priming test, followed in most cases by a test of recognition of the definitions of all the words in the stimulus set corresponding to the condition in which the subject was tested. In each session, items from one of the lists were presented at study, and items from the studied list plus items from a second (unstudied) list were presented, randomly interleaved, at test. Thus, each subject was tested on only two of the four lists. Lists were counterbalanced so that each was used a comparable number of times as a studied and an unstudied list.

Study session. The subjects read words aloud as they were presented one by one for $5 \mathrm{sec}$ each on the screen. The subjects in the unfamiliar-word conditions were told beforehand that the words were real English language words but that they were extremely low frequency words and may have been unfamiliar to them. If a subject mispronounced a word, the experimenter gave the correct pronunciation and instructed the subject to repeat the correct pronunciation aloud. We chose this study procedure because procedures that emphasize elaborative encoding can encourage declarative memory contamination of WSC priming (Richardson-Klavehn et al., 1994), because overt pronunciation of words enabled us to monitor encoding of unfamiliar words, and because overt pronunciation permitted us to explore possible phonological contributions to the WSC priming effect (see Experiment 2). We did not include other encoding manipulations, because we wanted to limit the scope of this investigation to the mechanisms underlying WSC priming and PI priming, as revealed by the familiarity manipulation. Half of the words of a 20-word list occurred once, and half occurred three times. Three-repetition words occurred in a randomly determined position within each third of the study list. In addition, 3 buffer words (taken from the remaining 24 stimuli) were inserted at the beginning and 3 buffer words at the end of each list, yielding a total of 46 stimulus-presentation events in each study list.

Word-stem completion priming test. Approximately $1 \mathrm{~min}$ after the study session, the subjects viewed 40 three-letter stems one by one. Half of the stems corresponded to words in the study list, and half to words in another of the four lists that served as unstudied words. Word stems corresponding to the two lists were interleaved randomly. The subjects were asked to think of each stem as the prefix to a word and to complete each stem with the first word (excluding proper nouns) that came to mind. For example, the stem FRA could be completed correctly with the words frame, fragrant, or fractal (the latter corresponding to the studied word). Each stem remained on the screen until the subject responded.

Word-stem completion recall test. The testing procedure differed from the WSC priming test in one respect only: The subjects were instructed to refer to the words that had been presented in the study list and to complete the word stems to as many studied words as possible.

Perceptual identification priming test. The subjects viewed 40 words one by one on the screen. The words were flashed tachistoscopically and backward masked (see Experiment 3 for details). Half of the words in each test had been presented in the previous study session. The other half were words that had not been studied. The priming effect was the number of correctly identified studied words minus the baseline score of correctly identified unstudied words.

Vocabulary recognition test. Immediately after the WSC priming or WSC recall tests, the subjects took a paper-and-pencil fouralternative forced-choice vocabulary test, measuring their understanding of the meanings of the 80 words that made up the stimulus set in the condition in which they had been tested. Each question contained the correct dictionary definition of the word, presented with three incorrect alternative definitions. The incorrect definitions, also taken directly from the dictionary (American Heritage), were definitions of words sharing the same prefix as the unfamiliar words or of words whose definitions seemed plausible candidates for the unfamiliar target word. The correct definition occurred an equal number of times in each of the four possible positions.

\section{Scoring}

We calculated stem completion (SC) priming and SC recall scores as the number of stems completed to studied words minus the baseline score of stems completed to unstudied words from the word list; we calculated PI priming scores as the number of studied words correctly identified minus the baseline score of the number of unstudied words correctly identified. Items were scored as correct only if they matched exactly the word (i.e., responses were scored as incorrect if only a single letter was omitted or misplaced).

\section{EXPERIMENT 1 Word-Stem Completion Priming}

Analysis of the WSC task indicated that it engages processes of lexical access. We hypothesized, therefore, that a modification mechanism, in which exposure to a familiar stimulus during a study session activates or modifies the lexical representation of the stimulus (Diamond \& Rozin, 1984; Graf et al., 1984; Shimamura \& Squire, 1984), makes a critical contribution to WSC priming. To test this hypothesis, we manipulated the familiarity of the stimuli that we presented to our subjects. The modification hypothesis assumes that a preexisting lexical representation of a word is necessary for priming with that word to occur on a WSC priming test and therefore predicts impaired WSC priming with unfamiliar words. (A corollary prediction of this lexical-access-based hypothesis is that baseline WSC to unfamiliar target words will be considerably lower than baseline WSC to familiar target words, because subjects are not expected to complete word stems to words that they do not know.) Acquisition explanations of WSC priming (e.g., Haist et al., 1991; Rajaram \& Roediger, 1993; Roediger et al., 1992; Schacter, 1992; Squire et al., 1992), in contrast, predict that subjects will perform normally on a test of WSC priming with unfamiliar words, because low-level perceptual mechanisms will be engaged equally by unfamiliar and familiar letter strings. We also tested WSC (cued) recall, in order to compare the priming results with the effects of the familiarity manipulation on the declarative memory analogue of the WSC priming test. In both tests, we included a manipulation of repetitions at study, because it has been used successfully in previous studies to draw inferences about the processes underlying the creation and strengthening of memory traces (Feustel, Shiffrin, \& Salasoo, 1983; Salasoo, Shiffrin, \& Feustel, 1985).

\section{Method}

The 49 subjects (mean age $=20.8$ years $[S D=2.2]$; mean Vocabulary score on the Wechsler Adult Intelligence Scale-Revised [WAIS $-\mathrm{R}]=12.9[S D=4.0]$ ) were divided randomly into four 


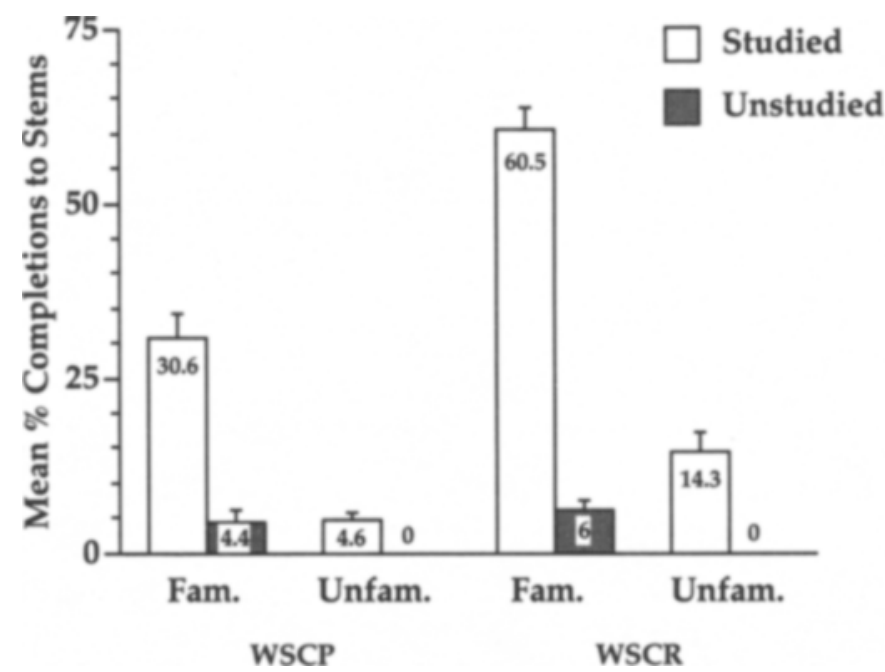

Figure 1. Results of Experiment 1: Word-stem completion priming (WSCP) and recall (WSCR).

groups: familiar WSC priming $(n=13)$, unfamiliar WSC priming $(n=14)$, familiar WSC recall $(n=11)$, and unfamiliar WSC recall $(n=11)$. The groups did not differ significantly in age or WAIS-R Vocabulary score.

The independent variables were familiarity (familiar or unfamiliar) and test type (WSC priming or WSC recall). The subjects were assigned randomly to one of the four cells of this $2 \times 2$ study design.

\section{Results}

Nonnormal distributions of dependent variables in some of the cells of our study precluded analysis with an analysis of variance (ANOVA). We therefore performed separate repeated measures analyses to test for significant levels of priming or recall in each test, then performed the relevant planned between-group comparisons.

\section{Vocabulary Recognition Test}

Initially, we confirmed that the familiar words were more familiar to our subjects than the unfamiliar words: The familiar WSC priming group scored significantly higher on the vocabulary recognition test $($ mean $=93.1 \%)$ than did the unfamiliar WSC priming group (mean = $39.4 \% ; t=4.8, p=.001$ ); similarly, the familiar WSC recall group scored significantly higher on the Vocabulary Recognition Test (mean $=95.4 \%$ ) than did the unfamiliar WSC recall group (mean $=42.0 \% ; t=15.5, p<$ .0001 ; chance $=25 \%$ correct). We suspect that the subjects in the unfamiliar condition used guessing strategies to perform above chance, because posttest debriefing indicated that, with a few isolated exceptions on individual items, the words in the unfamiliar stimulus pool were truly unfamiliar to the subjects.

\section{Priming Tests}

The subjects in the familiar WSC priming test correctly completed significantly more stems to studied words than to unstudied words $(t=6.8, p<.0001$; Fig- ure 1). Each of the subjects in this group showed a priming effect. In the unfamiliar WSC priming test, however, the difference between mean studied completions and mean unstudied completions did not achieve statistical significance $(t=1.8, p=.08)$. Only 2 of the 14 subjects in this group showed a priming effect (i.e., 2 subjects completed more stems to studied words than to unstudied words, whereas 12 subjects completed the same number or fewer stems to studied words than to unstudied words). In the familiar WSC priming test, the mean for completions to three-repetition words $(31.2 \%)$ was not significantly different from the mean for completions to onerepetition words $(29.2 \%)$. In the unfamiliar WSC priming test, five word stems were completed to three-repetition words and one word stem was completed to a onerepetition word. A Wilcoxon rank sums test indicated that familiar WSC priming was significantly greater than unfamiliar WSC priming $(p<.0001)$.

\section{Recall Tests}

The subjects in both WSC recall tests correctly completed significantly more stems to studied words ( $p=$ .001 , Mann-Whitney sign rank test; Figure 1). In the familiar WSC recall test, the mean for completions to three-repetition words $(72.7 \%)$ was significantly greater than the mean for completions to one-repetition words $(48.2 \% ; t=3.1, p=.01)$. In the unfamiliar WSC recall test, the mean for completions to three-repetition words $(22.3 \%)$ was significantly greater than the mean for completions to one-repetition words $(6.5 \% ; t=6.2, p<.0001)$. A Wilcoxon rank sums test indicated that familiar WSC recall was significantly greater than unfamiliar WSC recall $(p<.0001$; Figure 1$)$.

Within-condition comparisons of tests indicated that, within each condition, WSC recall scores were significantly greater than WSC priming scores (familiar, $t=5.8$, 
$p<.0001$; unfamiliar, $p<.0005$, Wilcoxon rank sums test).

\section{Discussion}

Experiment 1 produced a striking dissociation in WSC priming scores when we manipulated word familiarity: WSC priming with unfamiliar words was not statistically different from 0 , whereas WSC priming with familiar words that were matched closely for word length was robust. In both conditions, WSC recall scores were significantly higher than WSC priming scores. In the familiar condition, WSC recall performance was sensitive to a manipulation of repetitions at study, whereas WSC priming performance was not. A similar statistical analysis for the unfamiliar condition was not possible, because of low stem completions for studied words in the WSC priming test.

We interpret these results as being consistent with the modification model of WSC priming, because this model posits that WSC priming requires preexisting lexical representations of the stimulus material. We found no evidence for WSC priming with words that were unfamiliar to subjects, words for which we assume that subjects had no lexical representations (based on low vocabulary recognition test scores). These results are not consistent with perceptual models of WSC priming. For example, if the WSC priming effect arose from enhanced perception of three-letter stems that corresponded to studied words, the manipulation of a lexical independent variable (familiarity in our experiment) should have no influence on the results. A similar experimental approach was employed by Diamond and Rozin (1984), who reported impaired WSC recall in amnesic subjects with pseudoword stimuli. This earlier result was inconclusive about the role of modification in WSC priming, however, because the subjects were given recall instructions prior to the stem completion test. Our claim that WSC priming relies on interaction with the mental lexicon is consistent with reports that WSC priming is sensitive to level-of-processing manipulations (Carlesimo, 1994; Cermak, Mather, \& Hill, 1997; Graf et al., 1984; RichardsonKlavehn et al., 1994; but see Hamann \& Squire, 1996; Roediger et al., 1992) and with reports of dependency between WSC priming and confrontation naming performance in AD (Chertkow et al., 1996; Keane et al., 1991).

Our interpretation of these results is not weakened by the floor effect in the unfamiliar-word condition (baseline score of 0 ). Indeed, this result illustrates our assertion that disrupted lexical access (the process on which modification relies) is predicted when performance is scored on the completion of word stems to words for which subjects have no lexical representations.

We feel confident that the two WSC priming tests were valid measures of nondeclarative memory, because performance on these two tests dissociated in important ways from performance on the WSC recall tests, our measures of declarative memory in this experiment. First, WSC re- call scores were significantly higher than WSC priming scores in both conditions. Second, WSC recall was sensitive to the manipulation of study repetitions of stimulus items, whereas WSC priming was not.

Because the theoretical arguments presented in this paper rely heavily on the dissociation between familiar WSC priming and unfamiliar WSC priming, we conducted two additional experiments to confirm the reliability of this result.

\section{EXPERIMENT 2 \\ "Phonological" and "Orthographic" Stem Completion Priming}

Although the results of Experiment 1 were predicted by the modification hypothesis, it was possible that the absence of WSC priming with unfamiliar words in Experiment 1 was an artifact of the priming test instructions to "complete each stem to the first word that comes to mind." That is, studied unfamiliar words may have been the first words to come to mind for our subjects, but if they treated the unfamiliar words as nonwords (despite our instructions that these words were real but likely to be unfamiliar), they may have opted instead to complete stems with words with which they were familiar. We therefore investigated whether WSC priming can be supported by low-level perceptual representations, by modifying the instructions preceding the stem completion phase of the WSC priming test to encourage subjects to rely on phonology and orthography to complete the three-letter stems and by deemphasizing the need to complete the stems to familiar words. Again, the modification hypothesis predicted that the subjects would fail to show priming with unfamiliar words (and that baseline performance in the unfamiliar condition would be low), but acquisition hypotheses predicted normal priming with unfamiliar words.

\section{Method}

\section{Subjects}

The 64 subjects (mean age $=20.2$ years $[S D=1.8]$; mean WAIS$\mathrm{R}$ Vocabulary score $=14[S D=1.8]$ ) were divided randomly into four groups: familiar phonological SC priming $(n=16)$, unfamiliar phonological SC priming ( $n=15$ ), familiar orthographic SC priming $(n=17)$, and unfamiliar orthographic SC priming $(n=16)$. The groups did not differ significantly in age or WAIS-R Vocabulary score.

\section{Procedure}

The procedure for Experiment 2 was identical to that of the WSC priming portion of Experiment 1, with minor exceptions: In the phonological SC test, the instructions that preceded the test phase directed the subjects to complete each three-letter stem to the "first sound that comes to mind" (rather than to the "first word that came to mind"). In the orthographic SC test, the words were presented to the subject on a sheet of paper for $5 \mathrm{sec}$ during the study session, and the subject was instructed to read the word aloud. Immediately after the study session, the subject was given a pen and instructed to complete, by writing, the three-letter stem appearing on each sheet of paper with the first letter or letters coming to mind that could follow the stem to make a longer letter string. The instructions that preceded the test phase of both of these tests did not spec- 
Table 2

Mean Word-Stem Completion Scores From Experiment 2

\begin{tabular}{|c|c|c|c|c|c|c|c|c|}
\hline \multirow[b]{3}{*}{ Condition } & \multicolumn{4}{|c|}{$\begin{array}{l}\text { Phonological Word-Stem } \\
\text { Completion Priming }\end{array}$} & \multicolumn{4}{|c|}{$\begin{array}{l}\text { Orthographic Word-Stem } \\
\text { Completion Priming }\end{array}$} \\
\hline & \multicolumn{2}{|c|}{ Studied } & \multicolumn{2}{|c|}{ Unstudied } & \multicolumn{2}{|c|}{ Studied } & \multicolumn{2}{|c|}{ Unstudied } \\
\hline & $M$ & $S E$ & $M$ & $S E$ & $M$ & $S E$ & $M$ & $S E$ \\
\hline Familiar & 25.2 & 4.1 & 7.2 & 1.5 & 26.2 & $\overline{4.4}$ & 2.4 & 1.0 \\
\hline Unfamiliar & 2.3 & 0.8 & 0 & 0 & 2.3 & 1.0 & 0 & 0 \\
\hline
\end{tabular}

ify completion of stems to words. If a subject asked whether the stem completions needed to be words, the experimenter indicated that words, nonsense words, or nonverbal sounds were all acceptable, so long as the beginning of the stem completion corresponded to the three-letter stem.

\section{Results}

As in Experiment 1, we confirmed that the familiar words were more familiar to our subjects than the unfamiliar words: The familiar phonological SC group scored significantly higher on the Vocabulary Recognition Test (mean $=89.4 \%$ ) than did the unfamiliar phonological SC priming group (mean $=35.8 \% ; t=16.8, p<.0001$ ); the familiar orthographic SC group scored significantly higher (mean $=94.5 \%$ ) than did the unfamiliar orthographic SC priming group (mean $=40.9 \% ; t=24.1, p<$ .0001 ; chance $=25 \%$ ).

\section{Phonological Stem Completion Priming}

The subjects who performed the familiar phonological SC priming test correctly completed significantly more stems to studied words than to unstudied words $(t=6.8$, $p<.0001$; Table 2). Of the 16 subjects in this group, 15 showed a priming effect. For the subjects who performed the unfamiliar phonological SC priming test, the difference between the mean for studied completions and the mean for unstudied completions also achieved statistical significance $(t=2.8, p=.01)$. Of the 15 subjects in this group, 6 showed a priming effect. An item analysis of unfamiliar SC priming (restricted to the 6 subjects who showed a priming effect) revealed that, for the 7 trials in which stems were completed to studied words, $72.2 \%$ of the definitions of these studied words were selected correctly in the Vocabulary Recognition Test. By contrast, for the 291 trials in which stems were not completed to studied words, $43.7 \%$ of the definitions of these studied words were selected correctly in the Vocabulary Recognition Test. A Wilcoxon Rank Sums test indicated that familiar WSC corrected priming was significantly greater than unfamiliar WSC corrected priming $(p<.0001$; Table 2).

\section{Orthographic Stem Completion Priming}

The subjects who performed the familiar orthographic SC priming test correctly completed significantly more stems to studied words than to unstudied words $(t=5.7$, $p<.0001$; Table 2). Of the 17 subjects in this group, 15 showed a priming effect. For the subjects who performed the unfamiliar orthographic SC priming test, the difference between the mean for studied completions and the mean for unstudied completions also achieved statistical significance $(t=2.4, p=.03)$. Of the 16 subjects in this group, 6 showed a priming effect. An item analysis of unfamiliar orthographic SC priming (restricted to these 6 subjects) revealed that, for the 8 trials in which stems were completed to studied words, $72.2 \%$ of the definitions of the studied words were selected correctly in the Vocabulary Recognition Test. In contrast, for the 312 trials in which stems were not completed to studied words, $43.9 \%$ of the definitions were correctly selected in the Vocabulary Recognition Test.

\section{Discussion}

Our results indicated that familiar phonological SC priming was significantly greater than unfamiliar phonological SC priming, that familiar orthographic SC priming was significantly greater than unfamiliar orthographic SC priming, and that the unfamiliar priming effect in both tests was small but statistically significant. These results are broadly consistent with the predictions of the modification model of SC priming. The statistical significance of the unfamiliar phonological and orthographic SC priming effects, however, was not predicted by this model. There are two possible interpretations of the significant priming effect in the unfamiliar conditions of Experiment 2. The first is that the stems that were completed to studied words corresponded to words that were actually familiar to the subjects. This interpretation is suggested by the item analysis, which indicated that Vocabulary Recognition Test performance was dramatically higher for stems completed to target words than for stems that were not completed to target words. The second interpretation of the results is that perceptual codes can support a modest amount of SC priming.

\section{EXPERIMENT 3}

\section{Perceptual Identification Priming}

Considerable evidence supports the view that the learning observed in PI priming experiments depends unambiguously on perceptual mechanisms. For example, intact PI priming is found in normal and memoryimpaired subjects tested with pseudowords and unfamiliar words (Bowers, 1994, 1996; Cermak et al., 1991; Haist et al., 1991; Keane et al., 1994; Kirsner \& Smith, 
1974; Postle \& Corkin, 1998; Rueckl, 1990; Soloman \& Postman, 1952; Whitlow \& Cebollero, 1989; Whittlesea \& Cantwell, 1987), indicating that the learning is supported by the biasing of prelexical perceptual mechanisms (i.e., the learning cannot take place at the level of lexical representations). Intact PI priming with the unfamiliar words used in the previous experiments would demonstrate a dissociation from WSC priming, suggesting that the two types of priming rely on different mechanisms. This result would also indicate that the absence of a WSC priming effect with these same stimuli (Experiments 1 and 2) was not due to an idiosyncratic nonlearnability inherent in this stimulus set.

\section{Method}

\section{Subjects}

The 37 subjects (mean age $=20.7$ years $[S D=3.0]$; mean WAIS $-\mathrm{R}$ Vocabulary score $=13.0[S D=1.9]$ ) were divided randomly into two groups (familiar, $n=20$; unfamiliar, $n=17$ ). The groups did not differ significantly in age or WAIS-R Vocabulary score

\section{Design}

The experimental design of Experiment 3 was formally identical to the design of the SC priming experiments. Additional dependent measures for the PI priming experiment were threshold exposure duration and priming score $\times$ word length $($ short $<$ or $=8$ letters; long $>8$ letters).

\section{Procedure}

Threshold session. This session determined for each subject the stimulus exposure duration that would result in a $50 \%$ correct identification performance with unstudied words. An unstudied baseline performance of approximately $50 \%$ correct would ensure that the performance of the subjects on the PI priming test would not be contaminated by floor or ceiling effects. A fixation cross $(+)$ signaling the beginning of each trial appeared on the screen for $1,000 \mathrm{msec}$, followed by a 900 -msec blank interval, followed by a word presented for a variable exposure duration, followed immediately (ISI $=0 \mathrm{msec}$ ) by a pattern mask $250 \mathrm{msec}$ in duration. The subjects were instructed to read each word aloud and encouraged to guess. During the threshold session, we determined the $50 \%$ correct performance exposure threshold for each subject at each word length (long and short) by using an adaptive staircase procedure, the step method, that operates on the principle of maximum likelihood estimation (Simpson, 1989). After each presentation trial, the experimenter entered a score of correct or incorrect into the computer that controlled the shutters on the slide projectors, and the step method algorithm governing the computer used this information to adjust the exposure duration of each trial to converge on the $50 \%$ threshold. For each subject, the mean of the results of two threshold blocks yielded the exposure duration that was used during the priming test. Two threshold blocks used short words, and two used long words.

The vocabulary recognition test was administered to each subject in this experiment.

\section{Results}

\section{Vocabulary Test}

Results of the vocabulary recognition test confirmed that the familiar words were more familiar than the unfamiliar words to our subjects: The mean score for familiar words was $87.7 \%$, and the mean score for unfamiliar words was $34.3 \%(t=19.2, p<.0001 ;$ chance $=25 \%)$.

\section{Threshold Session}

A $2 \times 2$ mixed factors ANOVA analyzing the variable exposure duration ( $50 \%$ correct performance threshold) revealed main effects of familiarity $[F(1,35)=232.4$, $p>.0001]$ and word length $[F(1,35)=70.9, p<.0001]$ and an interaction $[F(1,35)=167.2, p<.0001$; Table 3$]$.

\section{Priming Test}

The subjects in both groups identified correctly more studied words than unstudied words (Figure 2). A $2 \times 2$ between- and within-factors ANOVA, with the factors of familiarity and study, revealed a main effect of study $[F(1,35)=206.9, p<.001]$ and an interaction $[F(1,35)=$ $4.2, p<.05]$. Post hoc $t$ tests confirmed that there was a significant priming effect for familiar words $(t=12.2$, $p<.0001)$ and for unfamiliar words $(t=8.0, p<.0001)$ and that the baseline scores of the two groups did not differ significantly (Figure 2).

Analysis of mean correct identification of studied words $\times$ repetitions at study, with a $2 \times 2$ between- and within-factors ANOVA, with factors of familiarity and repetitions at study, revealed a borderline main effect of familiarity $[F(1,35)=3.7, p=.06]$, a main effect of repetition $[F(1,35)=45.5, p<.0001]$, and an interaction $[F(1,35)=20.2, p<.0001]$. Post hoc $t$ tests confirmed that the source of the interaction was a significant difference between the mean identification scores for onerepetition familiar words and for one-repetition unfamiliar words $(t=4.0, p<.0005)$ and that there was no difference between the mean identification score for threerepetition familiar words and the mean score for threerepetition unfamiliar words (Table 4 ).

Analysis of priming effects $\times$ word length (familiar, short $=36.6 \%$, long $=40.2 \%$; unfamiliar, short $=26.5 \%$, long $=32.4 \%$ ) with a $2 \times 2$ between- and within-factors ANOVA, with factors of familiarity and priming score $X$ word length revealed a borderline main effect of familiarity $[F(1,35)=3.4, p=.07]$, no main effect of word length, and no interaction.

An item analysis of unfamiliar PI priming revealed that, for the 276 trials in which studied words were identified correctly, $33.5 \%$ of the definitions of these studied words were correctly selected in the vocabulary recognition test. And for the 59 trials in which studied words were not identified correctly, $36.3 \%$ of the definitions of these studied words were correctly selected in the vocabulary recognition test. These values did not differ statistically.

\section{Discussion}

We observed robust PI priming with familiar and unfamiliar words, and priming with familiar words was significantly higher than priming with unfamiliar words. Baseline identification levels for the two conditions were comparable. The manipulation of word length affected both subject groups in the same way, resulting in slightly (but not significantly) higher priming for long words than for short words. The manipulation of repetitions at study, however, affected the two groups differently: The 


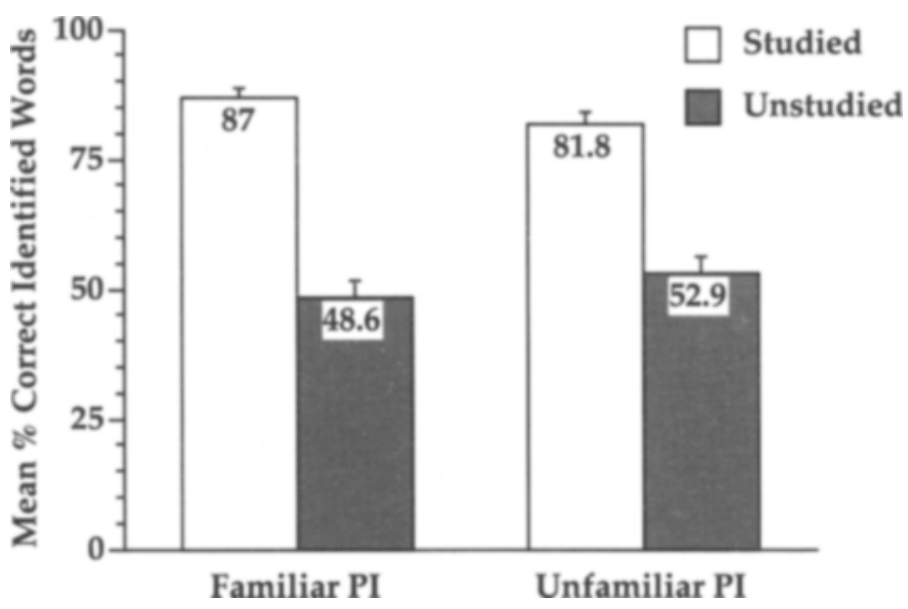

Figure 2. Results of Experiment 4: Perceptual identification priming.

subjects identified correctly more one-repetition familiar words than one-repetition unfamiliar words. Unlike with the SC priming tests presented in Experiment 2, successful performance on a studied item in the PI priming test was not associated with a higher probability of successful performance on that item on the Vocabulary Recognition Test.

Preserved PI priming with unfamiliar words is consistent with proposals that an acquisition mechanism is principally responsible for this effect (e.g., Keane et al., 1991; Reinitz \& Alexander, 1996) and is inconsistent with assumptions that PI priming and WSC priming are supported principally by the same mechanisms. The item analysis revealed a second important dissociation with SC priming: Word stems completed to target words in Experiment 2 were more likely to be familiar to subjects than were word stems not completed to target items; target words identified in the PI priming experiment, in contrast, were no more familiar to subjects than were target words that were not identified. This dissociation is consistent with the view that WSC priming requires interactions with lexical representations, whereas PI priming does not.

The study repetition $\times$ familiarity interaction in PI priming suggests that different mechanisms mediate PI priming with familiar and unfamiliar words. A strong interpretation of this view is that PI priming with familiar words may work on a principle of modification of graphemic representation units, whereas PI priming with unfamiliar words would result from interaction of the test stimuli with newly formed perceptual representations that were established by the study episode (an acquisition mechanism; Bowers, 1996; Whitlow, 1990). A less strong interpretation, derived from Feustel and colleagues (Feustel et al., 1983), posits that the same process of facilitation of perceptual processing through the acquisition of new perceptual representations is responsible for priming in each condition but that familiar-word PI priming gets an additional boost from interaction with stored lexical representations - the same modification mechanism that is responsible for WSC priming. Support for the latter position comes from the differential levels of word identification for one-repetition words that we found in the present study. The lower mean identification score for one-repetition words in the unfamiliar condition suggests that the new perceptual representation established by a single exposure to an unfamiliar word does not support priming to the same extent as does the coupling of a perceptual representation and a modified lexical representation, a phenomenon only possible with familiar words for which long-term representations already exist. The equivalent levels of priming for familiar and unfamiliar three-repetition words, however, suggest that multiple exposures to a stimulus quickly strengthen this perceptual representation to a point at which behavioral evidence for perceptual facilitation is at ceiling, and neither the benefit of modification of lexical representations nor that of further study exposures serves to increase the priming effect. Salasoo et al. (1985) reported repeatedexposure effects similar to what we have reported here and argued that the repeated-exposure effect is a manifestation of the codification of a representation. This model of one process mediating PI priming with familiar and with unfamiliar words (Feustel et al., 1983) offers a more parsimonious explanation of our results. It also illustrates an important theoretical conclusion of this paper, that a study episode can result in plastic change at several levels of information processing.

Table 3

Mean Exposure Duration (in Milliseconds) Determined by Perceptual Identification Threshold Test From Experiment 3

\begin{tabular}{lccrcc} 
& \multicolumn{2}{c}{ Short Words } & & \multicolumn{2}{c}{ Long Words } \\
\cline { 2 - 3 } \cline { 5 - 6 } Condition & $M$ & $S E$ & & $M$ & $S E$ \\
\hline Familiar & 63.2 & 13.4 & & 95.7 & 23.8 \\
Unfamiliar & 149.1 & 14.7 & & 544.1 & 39.7 \\
\hline
\end{tabular}


Table 4

Mean Perceptual Identification Percentage of Studied Completions by Repetitions at Study From Experiment 3

\begin{tabular}{lcc}
\hline Condition & One Repetition & Three Repetitions \\
\hline Familiar & 85 & 89 \\
Unfamiliar & 71.8 & 91.8 \\
\hline
\end{tabular}

\section{EXPERIMENT 4 \\ "Floor-Effect" Perceptual Identification Priming}

The interpretation of our data that we have emphasized throughout this report is that the dissociation of WSC priming and PI priming revealed by the familiarity manipulation illustrates important differences in the mechanisms that underlie these two examples of nondeclarative memory. This interpretation rests on a memory test $\times$ familiarity interaction that is observed across experiments. Interpretation of this interaction is rendered difficult, however, by floor effects in the WSC priming data (Loftus, 1978; Reinitz \& Alexander, 1996). Baseline scores of 0 in Experiments 1 and 2 raise the possibility that the interaction results from a scaling artifact in the WSC priming data and that, if WSC with unfamiliar words could be made less difficult, so that subjects would complete a reasonable number of unstudied word stems to target words, an unfamiliar-word priming effect might emerge. It is not possible, however, to raise baseline performance with unfamiliar words on the WSC task. Therefore, we designed Experiment 4 to generate an alternative solution to this problem: to produce PI data with a floor effect. This approach does not avoid the difficulties of interpreting data contaminated by floor effects. It does, however, permit a direct comparison of unfamiliar WSC priming and unfamiliar PI priming, an important test of our interpretation of our data. A demonstration of robust PI priming with unfamiliar words in floor effect conditions would permit the rejection of the scaling artifact interpretation of the interaction that emerged from Experiments 1-3.

\section{Method}

\section{Subjects}

The 20 subjects were divided randomly into two groups (familiar, $n=10$; unfamiliar, $n=10$ ).

\section{Procedure}

Threshold session. This session employed the same adaptive staircase algorithm as that used in Experiment 3. But rather than selecting the $50 \%$ correct performance level, the experimenter used each subject's performance on the threshold session to estimate the longest exposure duration that would yield a baseline score of $0 \%$.

Vocabulary Test. The Vocabulary Test was not administered in this experiment.

\section{Priming Test \\ Results \\ The subjects in both groups correctly identified more studied words than unstudied words (Table 5). A $2 \times 2$}

between- and within-factors ANOVA, with the factors of familiarity and study, revealed a main effect of study $[F(1,18)=75.5, p<.0001]$, indicating a significant priming effect but no main effect of familiarity and no interaction (Table 5).

An analysis of mean correct identification of studied words $\times$ repetitions at study, with a $2 \times 2$ between- and within-factors ANOVA, with factors of familiarity and repetitions at study, revealed a main effect of repetition [familiar three-repetition identification $=29 \%$, familiar one-repetition identification $=26 \%$, unfamiliar three-repetition identification $=39 \%$, unfamiliar onerepetition identification $=15 \% ; F(1,18)=12.5, p<$ $.005]$ and an interaction $[F(1,18)=7.6, p=.01]$. The interaction, as in Experiment 3, was due to the disparity in correct identifications $\times$ repetition in the unfamiliar condition.

\section{Discussion}

The results of Experiment 4 indicate that PI priming with unfamiliar words is not abolished when difficulty is increased to the point at which baseline scores are at the floor. This result makes the scaling artifact interpretation of our WSC priming data from Experiments 1 and 2 less plausible. To effect a direct comparison of PI priming and WSC priming with unfamiliar stimuli when baseline scores are comparable, we graphed together the subset of the PI data from Experiment 4 in which baseline scores were 0 and the WSC data from Experiment 1 (Figure 3). These results illustrate that the test $\times$ familiarity interaction remains when the two tasks are matched for difficulty, thereby reinforcing our interpretation that different mechanisms mediate priming with these two different tasks.

\section{GENERAL DISCUSSION}

We interpret the dissociation of WSC priming and PI priming as being a reflection of the procedural differences of the two tasks. Rather than invoking two types of processing (e.g., data-driven vs. conceptually driven) or two memory systems (e.g., perceptual and conceptual), we emphasize that the two tasks engage different cognitive mechanisms: lexical search and visual perception, respectively. The locus of learning in WSC priming is the lexical search process, which is biased by the modification mechanism. The loci of learning in PI priming are the visual perceptual mechanisms that permit detection of letter strings presented near the limits of temporal resolution of the visual system. Previous work has revealed dissociations between WSC priming and PI priming. In

Table 5

Mean Percentage of Correct Identification From Experiment 4

\begin{tabular}{|c|c|c|c|c|}
\hline \multirow[b]{2}{*}{ Condition } & \multicolumn{2}{|c|}{ Studied } & \multicolumn{2}{|c|}{ Unstudied } \\
\hline & $M$ & $S E$ & $M$ & $S E$ \\
\hline Familiar & 32 & 5.2 & 1 & 1.0 \\
\hline Unfamiliar & 31.5 & 4.8 & 3.5 & 1.8 \\
\hline
\end{tabular}




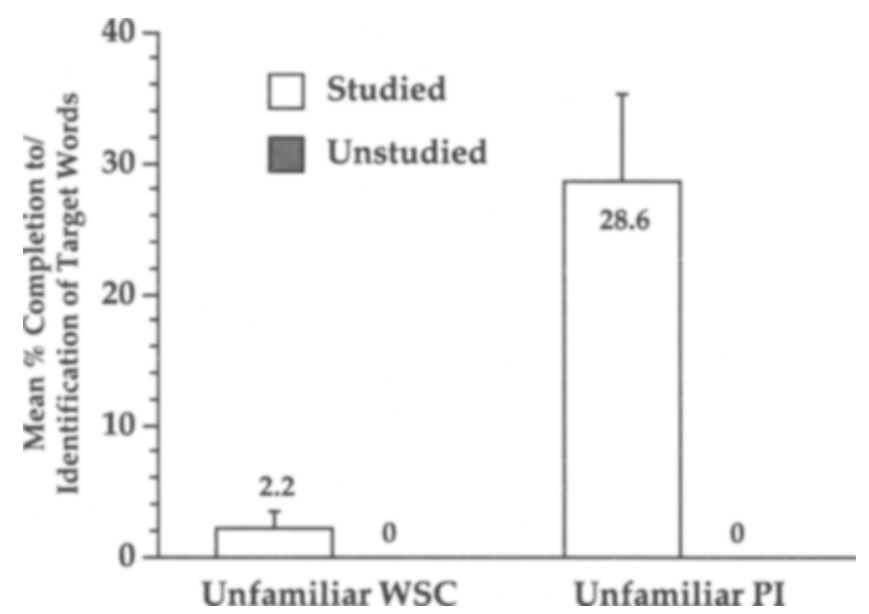

Figure 3. Comparison of unfamiliar word-stem completion priming from Experiment 1 and the subset of unfamiliar "floor-effect" perceptual identification priming data from Experiment 4 in which unstudied baseline scores were 0 .

our laboratory, patients with $\mathrm{AD}$ were impaired on tests of WSC priming but showed intact PI priming (Gabrieli et al., 1994; Keane et al., 1991; Keane et al., 1994). Rajaram and Roediger (1993) reported data indicating that WSC priming was preserved (albeit at a lower level) after a study-test modality shift but that PI priming was abolished by this manipulation. Previous studies from our laboratory suggest that the brain areas corresponding to these two different types of repetition priming are the heteromodal temporal-parietal cortex and the posterior visual cortex, respectively (Gabrieli et al., 1994; Keane et al., 1991; Keane et al., 1994; Keane, Gabrieli, Mapstone, Johnson, \& Corkin, 1995). A similar claim about different mechanisms underlying different kinds of repetition priming (WSC vs. word-fragment completion) has been made by Nyberg and colleagues (Nyberg, Winocur, \& Moscovitch, 1997). Together, these studies illustrate the power of the component processes approach to nondeclarative memory theorizing and challenge the assumption of several memory researchers that many types of repetition priming rely on the same perceptual mechanisms (e.g., Bowers, 1994; Hamann, 1996; Hamann \& Squire, 1996; Keane et al., 1997; Rajaram \& Roediger, 1993; Schacter, 1994). The dissociation of different repetition priming tests (and, therefore, of different kinds of nondeclarative memory) does not, however, challenge the importance of the declarative/nondeclarative distinction. Although many different types of repetition priming may rely on different mechanisms and different neural substrates, all share the common property that they do not rely on the medial temporal-diencephalic system that is specialized for declarative memory.

\section{REFERENCES}

The American Heritage Dictionary (2nd College ed.) (1991). Boston, MA: Houghton Mifflin.
AtKinson, R. C., \& JuOLA, J. F. (1974). Search and decision processes in recognition memory. In D. H. Krantz, R. C. Atkinson, R. D. Luce, \& P. Suppes (Eds.), Contemporary developments in mathematical psychology (pp. 243-293). San Francisco: Freeman.

BLAXTON, T. A. (1989). Investigating dissociations among memory measures: Support for a transfer appropriate processing framework. Journal of Experimental Psychology: Learning, Memory, \& Cognition, 15, 657-668.

BOWERS, J. S. (1994). Does implicit memory extend to legal and illegal nonwords? Journal of Experimental Psychology: Learning, Memory, \& Cognition, 20, 534-549.

BowERS, J. S. (1996). Different perceptual codes support priming for words and pseudowords: Was Morton right all along? Journal of Experimental Psychology: Learning, Memory, \& Cognition, 22, 1336-1353.

BowLER, P. (1992). The superior person's second book of weird and wondrous words. Boston, MA: David R. Godine.

Carlesimo, G. A. (1994). Perceptual and conceptual priming in amnesic and alcoholic patients. Neuropsychologia, 32, 903-921.

Cermak, L. S., Mather, M., \& Hill, R. (1997). Unconscious influences on amnesics' word-stem completion. Neuropsychologia, 35, 605-610.

Cermak, L. S., Verfaellie, M., Milberg, W., Letourneau, L., \& BLACKFORD, S. (1991). A further analysis of perceptual identification priming in alcoholic Korsakoff patients. Neuropsychologia, 29, 725-736.

Chertkow, H., Beauregard, M., Murtha, S., Bergman, H. Leblanc, S., Benhamou, J., \& Gold, D. (1996). The impact of semantic impairment on implicit memory function in Alzheimer's disease. Society for Neuroscience Abstracts, 22, 2119.

CHURCH, K. (1988). A stochastic parts program and noun phrase parser for unrestricted text. Paper presented at the Second Conference on Applied Natural Language Processing, Austin, TX.

DiAmond, R., \& Rozin, P. (1984). Activation of existing memories in anterograde amnesia. Journal of Abnormal Psychology, 93, 98-105.

DoRfMan, J. (1994). Sublexical components in implicit memory for novel words. Journal of Experimental Psychology: Learning, Memory, \& Cognition, 20, 1108-1125.

Evans, R. L., \& BERENT, I. M. (1993). Getting your words' worth. New York, NY: Warner Books.

Feustel, T. C., Shiffrin, R. M., \& Salasoo, A. (1983). Episodic and lexical contributions to the repetition effect in word identification. Journal of Experimental Psychology: General, 112, 309-346.

Forbach, G. B., Stanners, R. F., \& Hochhaus, L. (1974). Repetition and practice effects in a lexical decision task. Memory \& Cognition, 2, 337-339. 
Gabrieli, J. D. E., Keane, M. M., \& Corkin, S. (1990). Nonword priming may be robust despite global amnesia. Society for Neuroscience Abstracts, 16, 26.

Gabrieli, J. D. E., Keane, M. M., Stanger, B. Z., KJelgaard, M. M., Corkin, S., \& Growdon, J. H. (1994). Dissociations among structural-perceptual, lexical-semantic, and event-fact memory systems in amnesia, Alzheimer's disease, and normal subjects. Cortex, 30, $75-103$.

Gabrieli, J. D. E., Milberg, W., Keane, M. M., \& Corkin, S. (1990). Intact priming of patterns despite impaired memory. Neuropsychologia, 28, 417-427.

GRAF, P., \& SCHACTER, D. L. (1985). Implicit and explicit memory for new associations in normal and amnesic subjects. Journal of Experimental Psychology: Learning, Memory, \& Cognition, 13, 45-53.

GraF, P., SQuire, L. R., \& MANDler, G. (1984). The information that amnesic patients do not forget. Journal of Experimental Psychology: Learning, Memory, \& Cognition, 10, 164-178.

Haist, F., Musen, G., \& SQuire, L. R. (1991). Intact priming of words and nonwords in amnesia. Psychobiology, 19, 275-285.

HamanN, S. B. (1996). Implicit memory in the tactile modality: Evidence from braille stem completion in the blind. Psychological Science, 7, 284-288.

HAMANN, S. B., \& SQuiRE, L. R. (1996). Level-of-processing effects in word-completion priming: A neuropsychological study. Journal of Experimental Psychology: Learning, Memory, \& Cognition, 22, 933947.

Heindel, W. C., Salmon, D. P. Shults, C. W., Walicke, P. A., \& ButTERS, N. (1989). Neuropsychological evidence for multiple implicit memory systems: A comparison of Alzheimer's, Huntington's and Parkinson's disease patients. Journal of Neuroscience, 9, 582-587.

JACOBY, L. L., \& Dallas, M. (1981). On the relationship between autobiographical memory and perceptual learning. Journal of Experimental Psychology: General, 110, 306-340.

Keane, M. M., Gabrieli, J. D. E., Fennema, A. C., Growdon, J. H., \& CoRkIN, S. (1991). Evidence for a dissociation between perceptual and conceptual priming in Alzheimer's disease. Behavioral Neuroscience, 105, 326-342.

Keane, M. M., Gabrieli, J. D. E., Growdon, J. H., \& Corkin, S. (1994). Priming in perceptual identification of pseudowords is normal in Alzheimer's disease. Neuropsychologia, 32, 343-356.

Keane, M. M., Gabrieli, J. D. E., Mapstone, H. C., Johnson, K. A., \& CoRKIN, S. (1995). Double dissociation of memory capacities after bilateral occipital-lobe or medial temporal-lobe lesions. Brain, 118 1129-1148.

Keane, M. M., Gabrieli, J. D. E., Monti, L. A., Fleischman, D. A., CANTOR, J. M., \& Noland, J. S. (1997). Intact and impaired conceptual memory processes in amnesia. Neuropsychology, 11, 59-69.

KIRSNER, K., \& SMITH, M. C. (1974). Modality effects in word identification. Memory \& Cognition, 2, 637-640.

LA VoIE, D., \& Light, L. (1994). Adult age differences in repetition priming: A meta-analysis. Psychology \& Aging, 9, 539-553.

Light, L. L., \& KeNNISON, R. F. (1996a). Guessing strategies, aging, and bias effects in perceptual identification. Consciousness \& Cognition, 5, 463-499.

Light, L. L., \& KenNison, R. G. (1996b). Guessing strategies in perceptual identification: A reply to McKoon and Ratcliff. Consciousness \& Cognition, 5, 512-524.

LofTUS, G. R. (1978). On interpretation of interactions. Memory \& Cognition, 6, 312-319.

Masson, E. J. M., \& MacLeod, C. M. (1996). Contributions of processing fluency to repetition effects in masked word identification. Canadian Journal of Experimental Psychology, 50, 9-21.

MCKOON, G., \& RATCLIFF, R. (1996). Separating implicit from explicit retrieval processes in perceptual identification. Consciousness \& Cognition, 5, 500-511.

Meyer, D. M., \& Schvanaveldt, R. (1971). Facilitation in recognizing pairs of words: Evidence of a dependence between retrieval operations. Journal of Experimental Psychology, 90, 227-234.

Morton, J. (1970). A functional model for memory. In D. A. Norman
(Ed.), Models of human memory (pp. 203-254). New York: Academic Press.

Musen, G., \& Treisman, A. (1990). Implicit and explicit memory for visual patterns. Journal of Experimental Psychology: Learning, Memory, \& Cognition, 16, 127-137.

NyberG, L., WINOCUR, G., \& Moscovitch, M. (1997). Correlation between frontal lobe functions and explicit and implicit stem completion in healthy elderly. Neuropsychology, 11, 70-76.

Postle, B. R., \& CoRkIN, S. (1998). Impaired word-stem completion priming but intact perceptual identification priming with novel words: Evidence from the amnesic patient H.M. Neuropsychologia, 36, 421-440.

Postle, B. R., Corkin, S., \& Growdon, J. H. (1996). Intact implicit memory for novel patterns in Alzheimer's disease. Learning \& Memory, 3, 305-312.

Rajaram, S., \& Roediger, H. L., III (1993). Direct comparison of four implicit memory tests. Journal of Experimental Psychology: Learning, Memory, \& Cognition, 19, 765-776.

RATCLIFF, R., \& McKoon, G. (1997). A counter model for implicit priming in perceptual word identification. Psychological Review, 104, 319-343.

Ratcliff, R., McKoon, G., \& Verwoerd, M. (1989). A bias interpretation of facilitation in perceptual identification. Journal of Experimental Psychology: Learning, Memory, \& Cognition, 15, 378-387.

ReinitZ, M. T., \& AleXANDER, R. (1996). Mechanisms of facilitation in primed perceptual identification. Memory \& Cognition, 24, 129-135.

Richardson-Klatehn, A., Gardiner, J. M., \& JaVA, R. I. (1994). Involuntary conscious memory and the method of opposition. Memory, 2, 1-29.

RoEdiger, H. L., III (1990). Implicit memory. American Psychologist, 45, 1043-1056.

Roediger, H. L., III, Weldon, M. S., Stadler, M. L., \& Rigler, G. L. (1992). Direct comparison of two implicit memory tests: Word fragment and word stem completion. Journal of Experimental Psychology: Learning, Memory, \& Cognition, 18, 1251-1269.

RozIN, P. (1976). The psychobiological approach to human memory. In M. R. Rosenzweif \& E. L. Bennett (Eds.), Neural mechanisms of learning and memory (pp. 1-48). Cambridge, MA: MIT Press.

RUECKL, J. G. (1990). Similarity effects in word and pseudoword repetition priming. Journal of Experimental Psychology: Learning, Memory, \& Cognition, 16, 374-391.

Salasoo, A., Shiffrin, R. M., \& Feustel, T. C. (1985). Building permanent memory codes: Codification and repetition effects in word identification. Journal of Experimental Psychology: General, 114, 50-77.

Salmon, D. P., Shimamura, A. P., Butters, N., \& Smith, S. (1988). Lexical and semantic priming deficits in patients with Alzheimer's disease. Journal of Clinical \& Experimental Neuropsychology, 10, 477-494.

SCHACTER, D. L. (1992). Priming and multiple memory systems: Perceptual mechanisms of implicit memory. Journal of Cognitive Neuroscience, 4, 244-256.

SChacter, D. L. (1994). Priming and multiple memory systems: Perceptual mechanisms of implicit memory. In D. L. Schacter \& E. Tulving (Eds.), Memory systems 1994 (pp. 233-268). Cambridge, MA: MIT Press.

Shimamura, A. P., Salmon, D. P., Squire, L. R., \& Butters, N. (1987). Memory dysfunction and word priming in dementia and amnesia. Behavioral Neuroscience, 101, 347-351.

Shimamura, A. P., \& SQuire, L. R. (1984). Paired-associated learning and priming effects in amnesia: A neuropsychological study. Journal of Experimental Psychology: General, 113, 556-570.

Simpson, W. A. (1989). The step method: A new adaptive psychophysical procedure. Perception \& Psychophysics, 45, 572-576.

Soloman, R. L., \& Postman, L. (1952). Frequency of usage as a determinant of recognition thresholds for words. Journal of Experimental Psychology, 43, 195-201.

Squire, L. R., Knowlton, B., \& Musen, G. (1993). The structure and organization of memory. Annual Review of Psychology, 44, 453-495. 
Squire, L. R., Ojemann, J. G., Miezin, F. M., Petersen, S. E., Videen, T. O., \& Raichle, M. E. (1992). Activation of the hippocampus in normal humans: A functional anatomical study of memory. Proceedings of the National Academy of Sciences, 89, 1837-1841.

Tenpenny, P. L., \& Shoben, E. J. (1992). Component processes and the utility of the conceptually-driven/data-driven distinction. Journal of Experimental Psychology: Learning, Memory, \& Cognition, 18, 25-42.

Tulving, E., Schacter, D. L., \& Stark, H. A. (1982). Priming effects in word-fragment completion are independent of recognition memory. Journal of Experimental Psychology: Learning, Memory, \& Cognition, 8, 336-342.

Warrington, E. K., \& Weiskrantz, L. (1970). The amnesic syndrome: Consolidation or retrieval? Nature, 228, 628-630.

WELDON, M. S. (1991). Mechanisms underlying priming on perceptual tests. Journal of Experimental Psychology: Learning, Memory, \& Cognition, 17, 526-541.

WHITLOW, J. W., JR. (1990). Differential sensitivity of perceptual identification for words and pseudowords to test expectations: Implications for the locus of word frequency effects. Journal of Experimental Psychology: Learning, Memory, \& Cognition, 16, 837-851.

Whitlow, J. W., JR., \& CEBollero, A. (1989). The nature of word frequency effects on perceptual identification. Journal of Experimental Psychology: Learning, Memory, \& Cognition, 15, 643-656.

Whit tLesea, B. W. A., \& CANTWELl, A. L. (1987). Enduring influence of the purpose of experiences: Encoding-retrieval interactions in word and pseudoword perception. Memory \& Cognition, 15, 465-472.

Witherspoon, D., \& Moscovitch, M. (1989). Stochastic independence between two implicit memory tasks. Journal of Experimental Psychology: Learning, Memory, \& Cognition, 15, 22-30.

\section{NOTES}

1. The multiplicative and additive mechanisms described by Reinitz and Alexander (1996) map to the acquisition and modification mechanisms, respectively.

2. Many memory-systems-influenced studies have reported a dissociation between WSC priming and PI priming in Alzheimer's disease (e.g., Chertkow et al., 1996; Gabrieli et al., 1994; Heindel, Salmon, Shults, Walicke, \& Butters, 1989; Keane et al., 1991; Salmon, Shimamura, Butters, \& Smith, 1988; Shimamura, Salmon, Squire, \& Butters, 1987), which has been interpreted by some as evidence for important differences between these two tasks.

3. Word frequency was determined with a database of every wire story issued by the Associated Press during the period February, 1988-December, 1988, using a stochastic part-of-speech analyzer (Church, 1988). We used this database rather than more conventional published corpora because many of the unfamiliar and familiar words were of recent origin and would not have appeared in corpora that had been published several decades prior to the years of our study.

\begin{tabular}{llll} 
& & \multicolumn{1}{c}{$\begin{array}{c}\text { APPENDIX A } \\
\text { Unfamiliar Words }\end{array}$} \\
\hline ABOMASUM & COUVADE & INVULTUATION & \multicolumn{1}{c}{ SANDARAC } \\
ACCIDIE & CREODONT & MACRENCEPHALY & SCANDIUM \\
ADVOWSON & CRICOID & MINIFIDIANISM & SCOLEX \\
AFFLATUS & CURRASSOW & MISONEISM & SENENDOESY \\
AFFRIATE & DECANE & MONOPSONY \\
BALMACAAN & DELAINE & MOROLOGY & SERIEMA \\
BASTNAESITE & DESMID & NATROLITE & SHILL \\
BELEMNITE & DETUMESCENCE & OLIBANUM & SILOXANE \\
BLATHERSKITE & ENCOPRESIS & PARADIASTOLE & SOLANUM \\
BOUSTROPHEDON & EQUISETUM & PORIOMANIA & SPERRYLITE \\
BREDE & EXPERGEFACTION & PREPUCE & SPIEGELEISEN \\
BRIMBORION & FILARIA & QUAGGA & SPODUMENE \\
BROMIDROSIS & FLANCH & RADZIMIR & SQUALENE \\
BRUCCINE & FOUMART & RECTRIX & STEARATE \\
BURGONET & FRIPPET & REFOCILLATION & STICHOMYTHIA \\
CASTROPHRENIA & GARGANEY & REGUR & TORULA \\
CALOTTE & GLOSSOLALIA & REMONTADO & TRACHEID \\
CAVETTO & GRAPHOLAGNIA & RENIN & TRUNNION \\
CLIVIA & GRIFFONAGE & REPTATION & VENIREMAN \\
COMPLORATION & GROBIANISM & RESH & VERATRINE \\
CONTRECTATION & RETENE & VESICANT \\
CORYZA & HALIEUTICS & ROUP & WHIMBREL \\
COURGETTE & HALZOUN & SALLET & ZINKENITE \\
\hline
\end{tabular}


APPENDIX B

Familiar Words

\begin{tabular}{llll}
\hline AEROBICS & DERAILLEUR & HUMUS & PLASMID \\
AIKIDO & DETERGENT & INTERFERON & POTHEAD \\
AMARETTO & DISKETTE & JACUZZI & PROTOTYPE \\
AMNIOCENTESIS & DOMINATRIX & JUGGERNAUT & PSYCHEDELIC \\
APARTHEID & DORK & LIBBER & PULSAR \\
AQUARIAN & DREADLOCKS & LUMPECTOMY & QUASAR \\
ATTITUDE & DUMPSTER & MAMMOGRAM & RASTAFARIAN \\
BEANIE & FIDO & MAOISM & REGGAE \\
BIATHLON & FLACKERY & MARGARITA & REVERB \\
BIONICS & FLOOZY & MEDICARE & RORSCHACH \\
BISCOTTI & FRACTAL & MENSCH & SALSA \\
BLOCKBUSTER & FREEBEE & MELATONIN & SCAM \\
CASTLE & FRISBEE & MIDI & SCHLOCK \\
CELLULITE & FUTON & MOONIE & SCHTICK \\
CHARBROILER & GIRO & MOTORCROSS & SKIFFLE \\
CHICANO & MYLAR & SLEAZE \\
CHUGALUG & GLASPHALT & NAUGAHYDE & SONOGRAM \\
CILANTRO & GLITZ & NERD & SPRING \\
CORTISONE & GRANOLA & NEUROSCIENCE & STAGFLATION \\
CROCKPOT & GRIDLOCK & PALIMONY & TELETHON \\
CRYONICS & GRUNGE & PAPARAZZI & TERIYAKI \\
DECATHLETE & GULAG & PARAMEDIC & TRIATHLON \\
DEFOGGER & HACKER & PHEROMONE & VALLEY \\
DELI & HOLOGRAM & PICOGRAM & VELCRO \\
DEPRESSION & HOMOPHOBIA & PIXEL & ZINGER \\
\hline
\end{tabular}

(Manuscript received May 30, 1997;

revision accepted for publication February 20, 1998.) 